\title{
Underuse of spirometry by general practitioners for the diagnosis of COPD in Italy
}

\author{
G. Caramori1, G. Bettoncelli2, R. Tosatto33, F. Arpinelli3, G. Visonà3, \\ G. Invernizzi ${ }^{2}$, B.F. Novelletto2, A. Papi ${ }^{1}$, I.M. Adcock4 ${ }^{4}$ A. Ciaccia1
}

ABSTRACT: Underuse of spirometry by general practitioners for the diagnosis of COPD in Italy. G. Caramori, G. Bettoncelli, R. Tosatto, F. Arpinelli, G. Visonà, G. Invernizzi, B.F. Novelletto, A. Papi, I.M. Adcock, A. Ciaccia.

Background. The Global Initiative for Chronic Obstructive Lung Disease (GOLD) underlines that spirometry is the gold standard as the most reproducible, standardised, and objective way of measuring airflow limitation in the diagnosis and assessment of Chronic Obstructive Pulmonary Disease (COPD). However, studies undertaken in different countries have suggested a widespread underuse of spirometry by general practitioners to establish the diagnosis of COPD. Precise estimates of the prevalence of physician-diagnosed COPD in Italy are not currently available.

In collaboration with the Italian Academy of General practitioners (SIMG) we have investigated the degree of use of spirometry to establish the diagnosis of COPD in Italy.
Methods. A standardised questionnaire has been selfadministered to a sample of $\mathbf{2 4 2 5}$ Italian general practitioners (representing $5 \%$ of all the Italian doctors involved in general practice). They have been chosen to cover each of the Italian counties.

Results. The prevalence of physician-diagnosed COPD was found to be approximately $4 \%$. However, $30 \%$ of general practitioners do not use spirometry to establish the diagnosis of COPD. The main reasons given for the failure to use spirometry are (i) that spirometry is not necessary for the diagnosis of COPD or (ii) there are logistical limitations to the access of the patients to lung function laboratories.

Conclusions. This data suggests that contrary to GOLD Guidelines, in Italy, as with other countries, spirometry is not always used in the diagnosis of COPD. There is a clear necessity for further education initiatives targeted to this group of physicians.

Monaldi Arch Chest Dis 2005; 63: 1, 6-12.

Keywords: General practitioners, COPD, Spirometry, Diagnosis, GOLD Guidelines.

1 Centro di Ricerca su Asma e BPCO, University of Ferrara, Italy

2 Gruppo CORDIS on behalf of the Società Italiana di Medicina Generale (SIMG), Firenze, Italy

3 Direzione Medica, GlaxoSmithKline, Verona, Italy

4 Airway Disease Section, National Heart and Lung Institute, Imperial College London, London, UK

Correspondence: Gaetano Caramori MD, PhD, Centro di Ricerca su Asma e BPCO, Via Savonarola 9, University of Ferrara, 44100 Ferrara, Italy; e-mail: crm@unife.it

This work has been funded by GSK (Italy).

\section{Introduction}

Chronic Obstructive Pulmonary Disease (COPD) is currently defined as "a disease state characterised by airflow limitation that is not fully reversible. The airflow limitation is usually progressive and associated with an abnormal inflammatory response of the lungs to noxious particles or gases" [1]. COPD is a major worldwide respiratory public health problem and one of the leading causes of morbidity and mortality among the adult population in industrialised and developing countries [2]. Cigarette smoking is the major risk factor for the development of COPD and cigarette smokers constitute over $90 \%$ of COPD patients in developed countries [3]. COPD has been increasingly recognised as a chronic inflammatory disease of the lower airways, which undergoes recurrent exacerbation of symptoms associated, in most cases, with exacerbation of the degree of airway inflammation [1]. There is increasing interest in characterising the type and intensity of airway inflammation, and in investigating whether it provides useful information for the management of disease. For example, do COPD patients with significant reversibility after a course of glucocorticoids have the pathological characteristics of asthma? However, the diagnosis, the assessment of severity, and the monitoring of COPD still rely on lung function tests [4].

Spirometry is essential for diagnosis because COPD is characterised by chronic airflow obstruction [forced expiratory volume in one second $\left(\mathrm{FEV}_{1}\right)$ /forced vital capacity (FVC) post-bronchodilator ratio $<70 \%]$ that does not change significantly, spontaneously or with treatment [1].

During the last 20 years our knowledge of the pathogenesis of COPD has made enormous advances, revolutionising the diagnostic approach and 
treatment (3). According to the evidence-based medicine approach, this new knowledge has been structured in National and International guidelines [1].

Specifically, the guidelines of the World Health Organization (WHO) have been translated in Italy (under the headings "Progetto Mondiale BPCO") and have been approved by all the leading scientific societies in Italy involved in the treatment of patients with COPD [1]. However many studies have shown that the guidelines, although disseminated among healthcare providers, are rarely applied in primary care. Although the extent to which COPD is underdiagnosed by Italian general practitioners is not known, under-diagnosis is a significant problem in the United States of America (USA) [5]. Little is known in Italy about general practitioners' knowledge and practice patterns for patients with COPD.

However, there are several reasons to suspect that family physician's knowledge and adherence to recommended guidelines is modest at best [6]. Furthermore, precise estimates of the prevalence of physician-diagnosed COPD in Italy are not available in literature. On the basis of this observation, the Respirology group of the Italian Academy of General practitioners (Società Italiana di Medicina Generale - SIMG), has carried out an observational study, under the acronym CORDIS (Chronic Obstructive Respiratory Disease - Italian Study), with the aim of evaluating the knowledge on COPD of the Italian general practitioners. This study consisted of two phases (CORDIS-A; and CORDIS-B). The data taken from CORDIS-A and the COPD questionnaire is reported here. The data of the CORDIS-A on asthma and all the data from the CORDIS-B will be the subject of future communications.

\section{Methods}

The CORDIS-A was carried out between April 2002 and May 2002 and involved 2,425 general practitioners (representing $5 \%$ of all the Italian physicianss involved in general practice). They have been chosen by the SIMG to cover all the Italian counties and for their willingness to participate at the study (fig. 1). Data was collected by general practitioners that privately filled in a hard copy of a self-administered questionnaire that was subsequently read anonymously by optical instruments (Appendix 1).

The questionnaire (the Italian and the English versions are freely available online at http://www.simg.it/pneumo/attivita/cordis/nf02r02 A\%20(2).pdf and http://www.simg.it/pneumo/attivita/cordis/QuestionnaireCORDISAEnglish5Ma y2004\%20revised.pdf) was divided in three sections: the first section dealt with the physicians details (age, gender, address), professional details [geographic area of Italy (North, Centre, South/ Islands according to the Italian National Institute of Statistic (ISTAT) classification, number of patients], which is the system used for recording the patient's data (electronic database, software used, main data kept on record); the second section dealt with the physicians perception of physician-diagnosed COPD in their practice (prevalence over

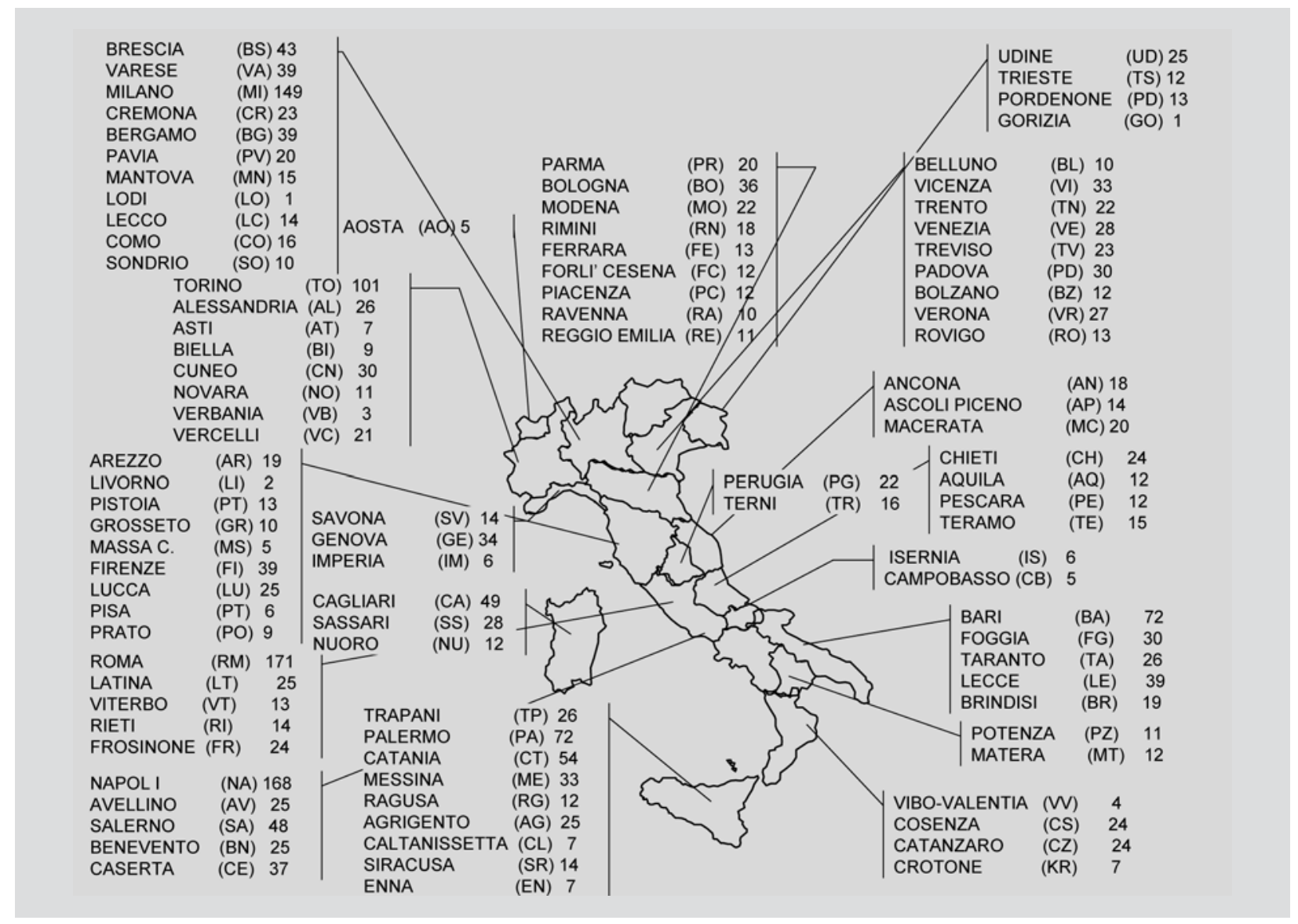

Fig. 1. - Distribution of the Italian general practitioners participating to the study according to their geographical area. 
time, level of control of the disease); the third section dealt with the management of patients affected by COPD (method of diagnosis, use of spirometry, prescription of specialist examinations, aims pursued during treatment).

Statistical analysis was carried out by an independent company specialising in medical statistics (Qubisoft, Padova, Italy).

\section{Results}

A total of 2,424 questionnaires were analysed after eliminating one questionnaire that was incomplete. The mean age of the sample of Italian general practitioners that completed the questionnaire was 48 (SD 4.9) years, with a prevalence of males $(88.5 \%)$. When divided according to their geographical area, $43.7 \%$ of the general practitioners were residents in the North, $18.1 \%$ in Central Italy and $38.3 \%$ in the South and Islands. Most general practitioners $(90.7 \%)$ have between 1,000-1,500 patients registered at their practice, and $85.6 \%$ use an electronic database, but many different software packages [the most frequent used $(19.9 \%)$ was Millewin (Datamat, Firenze, Italy)]. The data most commonly registered was patients' personal details (98.2\%), chronic pharmacological treatment $(96.9 \%)$ and diagnosis $(95.8 \%)$.

Most of the general practitioners (90.2\%) feel that COPD prevalence has increased in Italy over the past ten years, and $(89.5 \%)$ that patients with COPD are better controlled primarily due to early diagnosis and the availability of more effective treatments.

The mean number of COPD patients per general practitioner with 1000-1500 registered patients was 50.2 (SD 35.3) (fig. 2).

The main symptoms used for diagnosing COPD were the presence of chronic cough $(86.2 \%)$, expectoration $(85.6 \%)$ and exercise dyspnea $(51.5 \%)$. Spirometry was used to confirm the diagnosis by only $69.8 \%$ of the Italian general practitioners (fig. 3). A similar percentage of general practitioners declared that they classify the severity of COPD according to the stages proposed by the GOLD guidelines. A high percentage (48.2\%) of general practitioners reported to be able to diagnose COPD independently. The main reasons given by the Italian general practitioners for the failure to use spirometry are (i) there are logistical limitations to the access of the patients to lung function laboratories $(63.3 \%)$ or (ii) that spirometry is not necessary for the diagnosis of COPD (fig. 4).

The primary goals of drug therapy for COPD were to reduce the number of COPD exacerbations $(87.2 \%)$, to control the symptoms $(79.3 \%)$ and to improve the quality of life of the patients (54.7\%). The main reasons for which patients with COPD refer to general practitioners are to have a new prescription of the same drug $(78.6 \%)$ or to change treatment $(53.2 \%)$. Most of the general practitioners (62.1\%) feel that the management of the COPD patients is similar to that of other chronic diseases. Most of the Italian general practitioners $(68.3 \%)$ send their patients with COPD to a specialist consultation one or more times a year.

\section{Discussion}

The very high percentage of returned questionnaires could be explained by the inclusion criteria, because it has been administered only to the general practitioners that have selected by the SIMG for their willingness to participate to the study. Also the questionnaire had been self-administered and returned on the same day.

Despite all the limitations inherent with a retrospective epidemiological study based on a self-administered questionnaire, the large sample of general practitioners involved allowed us to draw some interesting conclusions. First of all, the sample of Ital- 


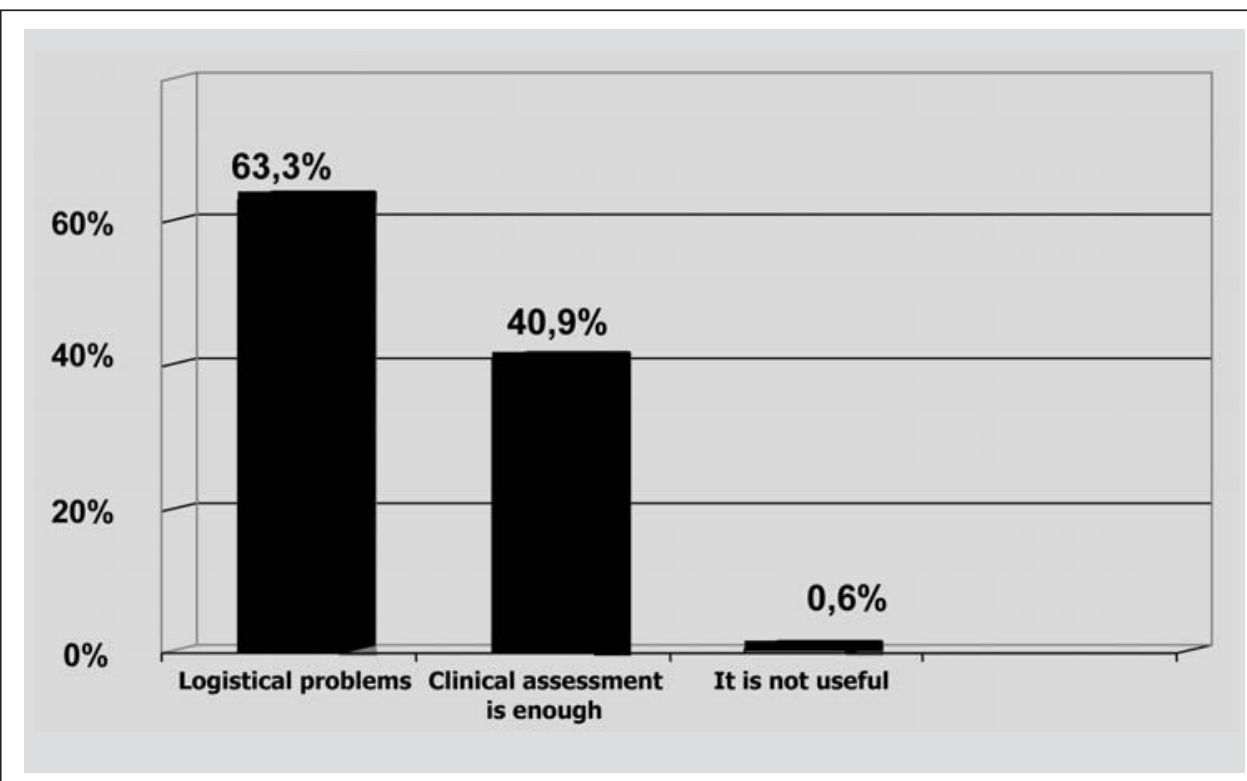

Fig. 4. - Main reasons for the failure to use spirometry for the diagnosis of COPD by general practitioners in Italy.

mary care setting has been recommended recently in the USA by the National Lung Health Education Program [8] and after an appropriate training seems feasible [9]. The implementation of the office spirometry has also been tried in Italy, with a pilot study (Project VEMS; the Italian acronym for forced expiratory volume in one second; [10]) but the preliminary results have been disappointing and the project has been stopped. Further studies are required to implement the GOLD

ian general practitioners involved in the study is significantly homogeneous with respect to age $(68.6 \%$ of them were between 41-50 years), they have a large number of patients in their practices and most of them have an electronic database record of their patients. All these factors may have contributed to their decision to participate in this study. Most general practitioners in Italy know the most common symptoms of COPD, however many still do not recognise that the COPD patients may be asymptomatic for many years and for this reason the diagnosis must be suspected much earlier according to their smoking history [1].

General practitioners in Italy probably diagnose only a fraction of all COPD patients (probably the most severe) and only about $70 \%$ of these underwent spirometry. The significant underuse of spirometry for the diagnosis and severity assessment of COPD by general practitioners in Italy suggests the need to implement more specific educational programmes targeted at this group of doctors.

Finally, the data concerning the renewal of the prescription or the aggravation of symptoms for attending clinic, suggests that general practitioners tend to treat patients with clear symptoms rather than make an early diagnosis aiming to help patients avoid exposure to risk factors, such as tobacco smoking. International and National guidelines for COPD are now available [1]. However, the implementation of these guidelines requires that general practitioners are willing to conform to those patterns of diagnosis and treatments and this may not happen in practice [7]. Early studies show that COPD care starts from an even lower baseline than asthma suggesting that there is poor understanding of objective diagnosis of COPD in primary care [7].

Overall general practitioners in Italy seem to have a good understanding of the increasing burden of COPD in their daily clinical practice. However, the declared use of spirometry seems to be inadequate and requires specifically targeted programmes to correct this deficiency. Implementation of a new type of office spirometry in the pri- guidelines approach to the diagnosis of COPD by general practitioners in Italy.

Acknowledgements: We would like to thank the pharmaceutical representatives of GlaxoSmithKline Italy who delivered and collected the questionnaires to the general practitioners.

\section{References}

1. Global Initiative for Chronic Obstructive Lung Disease. Global Strategy for the Diagnosis, Management and Prevention of Chronic Obstructive Pulmonary Disease. NHLBI/WHO workshop report. Bethesda, National Heart, Lung and Blood Institute, April 2001; NIH Publication No 2701:1-100. Updated 1 July 2003. http://www.goldcopd.com (accessibility verified 18 May 2004). The Italian translation is available online at http://www.goldcopd.it

2. Ramsey SD, Sullivan SD. The burden of illness and economic evaluation for COPD. Eur Respir J 2003; 41(suppl): 29s-35s.

3. Barnes PJ. Chronic obstructive pulmonary disease. $N$ Engl J Med 2000; 343: 269-280.

4. Caramori G, Adcock IM. Pharmacology of airway inflammation in asthma and COPD. Pulm Pharmacol Ther 2003; 16: 247-277.

5. Coultas DB, Mapel D, Gagnon R, Lydick E. The health impact of undiagnosed airflow obstruction in a national sample of United States adults. Am J Respir Crit Care Med 2001; 164: 372-377.

6. Ramsey SD. Suboptimal medical therapy in COPD: exploring the causes and consequences. Chest 2000; 117(2 Suppl): 33S-37S.

7. Pearson MG. How can the implementation of guidelines be improved? Chest 2000; 117(2 Suppl): 38S-41S.

8. Ferguson GT, Enright PL, Buist AS, Higgins MW. Office spirometry for lung health assessment in adults: A consensus statement from the National Lung Health Education Program. Chest 2000; 117: 1146-1161.

9. Schermer TR, Jacobs JE, Chavannes NH, Hartman J, Folgering HT, Bottema BJ, Van Weel C. Validity of spirometric testing in a general practice population of patients with chronic obstructive pulmonary disease (COPD). Thorax 2003; 58: 861-866.

10. http://web.unife.it/progetti/vems/(accessibility verified 18 May 2004) 
Appendix 1. - Questionnaire used for the study CORDIS-A

Date filled in

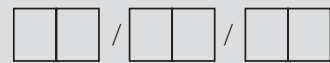

Patient Number

Sex $\square$ M $\quad \square$ F Age $\square \square$

\section{Province/county $\square \square$}

How many years have you worked in the Italian National Health Service?

Number of patients $\square 500-000$

What kind of area do you serve?

$$
\begin{aligned}
& \square \text { city } \\
& \square \text { suburb of city } \\
& \square \text { large town ( } 25,000 \text { to } 100,000 \text { people) } \\
& \square \text { small town (up to } 25,000 \text { people) } \\
& \square \text { rural area }
\end{aligned}
$$

Do you regularly use a computerised database in your practice?

$$
\begin{aligned}
& \square \text { database in your pra } \quad \square \text { No } \\
& \square \text { Yes }
\end{aligned}
$$

If Yes, what software application do you use? $\square$ Millewin

$$
\begin{aligned}
& \square \text { Millenet } \\
& \square \text { Perseo } \\
& \square \text { Profim } \\
& \square \text { Other }
\end{aligned}
$$

Do you regularly enter the following data in your database?
patient details
$\square$ YES
diagnosis
$\square$ YES
diary
$\square$ YES
regular treatment
$\square$ YES
$\square$ YES
$\square$ YES
as needed treatment
$\square$ YES
certificates (sickness, disability, school return)
death of the patient
$\square$ YES

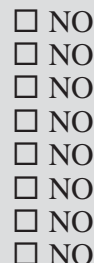

\section{The following questions are to understand the General Practitioner perception's of asthma and COPD}

1. In your opinion, the percentage of patients with COPD in Italy in the last 10 years has:

$$
\begin{aligned}
& \square \text { increased } \\
& \square \text { decreased } \\
& \square \text { unchanged } \\
& \square \text { don't know }
\end{aligned}
$$

2. In your opinion, the percentage of patients with asthma in Italy in the last 10 years has:

$$
\begin{aligned}
& \square \text { increased } \\
& \square \text { decreased } \\
& \square \text { unchanged } \\
& \square \text { don't know }
\end{aligned}
$$

3. In you opinion, compared with the past, the control of asthmatic patients is:

$$
\begin{aligned}
\text { improved } & \text { go to question } 3 \mathrm{a} \\
\text { worsened } & \text { go to question } 3 \mathrm{~b} \\
\text { unchanged } & \square \text { go to question } 4 \\
\text { don't know } & \text { go to question } 4
\end{aligned}
$$

3a. Which of the following factors contribute to the improvement of asthma control? (maximum 5 answers)

$\square$ a better understanding of the pathogenesis

$\square$ better monitoring methods

$\square$ earlier diagnosis

$\square$ better treatment (not only with drugs)

$\square$ simpler devices (eg. inhalers)

$\square$ decreased tobacco smoking

$\square$ better control of pollution

$\square$ better control of allergens and environmental causes

$\square$ greater patient compliance

3b. Which of the following factors contribute to the worsening of asthma control? (maximum 5 answers)

$\square$ poor dissemination of advances in knowledge

$\square$ poor application of monitoring methods

$\square$ late diagnosis

$\square$ worse treatment (not only with drugs)

$\square$ less effective drugs

$\square$ devices difficult to use (eg. inhalers)

$\square$ rise in cigarette smoking

$\square$ increased pollution

$\square$ poor control of allergens and environmental causes

$\square$ poor patient compliance 


\section{continued Appendix 1}

4. In your opinion, compared with the past, the control of COPD patients is:

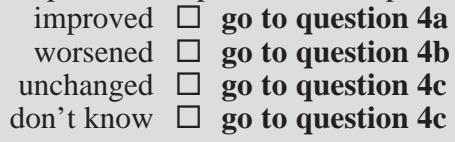

4a. Which of the following factors contribute to the improvement of COPD control? (maximum 5 answers)
$\square$ a better understanding of the pathogenesis
$\square$ better monitoring methods
$\square$ earlier diagnosis
$\square$ better treatment (not only with drugs)
$\square$ simpler devices (eg. inhalers)
$\square$ decreased tobacco smoking
$\square$ better control of pollution
$\square$ better control of allergens and environmental causes
$\square$ greater patient compliance

4b. Which of the following factors contribute to the worsening of COPD control? (maximum 5 answers)
$\square$ poor dissemination of advances in knowledge
$\square$ poor application of monitoring methods
$\square$ late diagnosis
$\square$ worse treatment (not only with drugs)
$\square$ less effective drugs
$\square$ devices difficult to use (eg. inhalers)
$\square$ rise in cigarette smoking
$\square$ increased pollution
$\square$ poor patient compliance

4c. How do you usually keep up to date in asthma and COPD?
$\square$ Journals
$\square$ Web
$\square$ Meetings
$\square$ Representatives
$\square$ Traditional training courses $\quad \square$ Web-based training courses

\section{The following questions are to understand the patient management by the General Practitioners}

5. What signs and symptoms do you routinely consider most important in the diagnosis of asthma? (maximum 5 answers)

$\square$ chronic cough

$\square$ coughing (particularly at night-time or early in the morning)

$\square$ dyspnea (breathlessness) at rest

$\square$ dyspnea (breathlessness) during exercise

$\square$ chest tightness at rest

$\square$ chest tightness during exercise

$\square$ concomitant atopic diseases

$\square$ sputum

$\square$ signs of cardiac failure (peripheral oedema, cyanosis)

$\square$ wheezing

6. What signs and symptoms do you routinely consider most important in the diagnosis of COPD? (maximum 5 answers) $\square$ chronic cough

$\square$ coughing (particularly at night-time or early in the morning)

$\square$ dyspnea (breathlessness) at rest

$\square$ dyspnea (breathlessness) during exercise

$\square$ chest tightness at rest

$\square$ chest tightness during exercise

$\square$ concomitant atopic diseases

$\square$ sputum

$\square$ signs of cardiac failure (peripheral oedema, cyanosis)

$\square$ wheezing

7. Do you routinely require a spirometry to confirm your asthma and COPD diagnosis?
Asthma
$\square$ YES
$\square \mathrm{NO}$
COPD
$\square$ YES
$\square \mathrm{NO}$

If NOT, why? $\square$ it is unnecessary

$\square$ clinical findings are enough

$\square$ logistical problems for the patient

8. Do you routinely stage your asthmatic patients according to guidelines?
$\square$ YES
$\square \mathrm{NO}$
If NOT, why? $\square$ it is useless for patient management $\square$ it is not possible 


\section{continued Appendix 1}

9. Do you routinely stage your COPD patients according to guidelines?
$\square$ YES
$\square \mathrm{NO}$
If NOT, why? $\square$ it is useless for patient management $\square$ it is not possible

10. In your opinion, can asthma and COPD be diagnosed by the General Practitioner alone?
$\square$ Always
$\square$ Never
$\square$ Not always

11. In your opinion which are the aims of an optimal asthma treatment? (maximum 4 answers)
$\square$ daytime and night-time symptoms control
$\square$ prevention of severe exacerbations
$\square$ to reduce or abolish the use of rescue medications
$\square$ improvement in the patient's quality of life
$\square$ to reduce the number of absences from school or work
$\square$ to reduce the number of specialist visits
$\square$ to simplify the treatment (once daily/fixed combinations)
$\square$ to prevent or reduce the decline in lung function

12. What in your opinion should be the aims of an optimal COPD treatment? (maximum 4 answers)

$\square$ control of respiratory symptoms (cough, sputum, dyspnea)

$\square$ to reduce the number of severe exacerbations

$\square$ to reduce the frequency of hospital admissions

$\square$ to prevent or reduce the decline in lung function

$\square$ to improve the patient's quality of life (to permit the carrying out of normal daily activities)

$\square$ to improve exercise tolerance

$\square$ to decrease mortality

$\square$ to reduce the number of specialist visits

$\square$ to simplify the treatment (once daily/fixed combinations)

13. What is the average number of patients with asthma and COPD you see during each year?
Asthma $\square \square$
COPD $\square \square$

14. What is the main reason that patients come to see you?
$\square$ to repeat prescriptions
$\square$ to obtain a specialist visit
$\square$ to modify the treatment
$\square$ to obtain a medical certificate

15. Do you have the same communication problems with your asthma and COPD patients as with other patients with chronic disease?
$\square$ YES
$\square \mathrm{NO}$

$$
\begin{aligned}
& \text { If NOT, is it } \square \text { easier } \\
& \square \text { more difficult }
\end{aligned}
$$

16. Do you periodically request specialist visits or pulmonary function tests for your asthma and COPD patients?
$\square$ Not
$\square$ Occasionally
$\square$ Yes, at least once a year

$\square$ Yes, more than once a year 